\title{
GENERALIZATION OF A BIHARI TYPE INTEGRAL INEQUALITY FOR ABSTRACT LEBESGUE INTEGRAL
}

\author{
LÁSZLÓ HORVÁTH
}

\begin{abstract}
In this paper we study some integral inequalities in measure spaces which are natural generalizations of special Bihari type integral inequalities. Explicit upper bounds for the solutions are given. The classical arguments can not be extended to this more general situation, we develop new methods. The results are applied to establish the existence of a solution to the corresponding integral equations.
\end{abstract}

Mathematics subject classification (2000): 26D15, 45G10.

Key words and phrases: Integral inequalities, measure spaces, abstract Lebesgue integral.

\section{REFERENCES}

[1] I. BIHARI, A generalization of a lemma of Bellman and its application to uniqueness problems of differential equations, Acta Math. Acad. Sci. Hungar., 7, (1956), 81-94.

[2] C. CORDUNEANU, Integral Equations and Applications, Cambridge University Press (1991).

[3] L. HoRvÁtH, Integral inequalities in measure spaces, J. Math. Anal. Appl., 231, (1999), 278-300.

[4] L. HoRvÁtH, On the associativity of the product of measure spaces, Acta Math. Hungar., 98, 4 (2003), 301-310.

[5] L. HoRvÁth, Integral equations in measure spaces, Integr. Equ. Oper. Theory, 45, (2003), 155-176.

[6] L. HoRváth, Generalizations of special Bihari type integral inequalities, Math. Inequal. Appl., 8, (2005), 441-449.

[7] L. HoRVÁTH, Nonlinear integral equations with increasing operators in measure spaces, J. Integr. Equ. Appl., 17, 4 (2005), 413-437.

[8] D. S. MitrinOviĆ, J. E. PeČARIČ AND A. M. FInK, Inequalities Involving Functions and Their Integrals and Derivatives, Kluwer Academic, Dordrecht (1991). 